\title{
Surgical outcomes of two kinds of demineralized bone matrix putties/local autograft composites in instrumented posterolateral lumbar fusion
}

Dong-Gune Chang ${ }^{1}$, Jong-Beom Park ${ }^{2,3 *}$ and Yangjun $\operatorname{Han}^{2}$

\begin{abstract}
Background: This study aimed to assess the surgical outcomes of two kinds of demineralized bone matrix (DBM) putties/local autograft composites in instrumented posterolateral lumbar fusion (PLF).

Methods: Twenty-seven fusion segments of 19 patients, who underwent decompression and instrumented PLF for lumbar spinal stenosis or degenerative spondylolisthesis less than grade 1, were included in this study. The PLF mass consisted of different two kinds of DBMs (Grafton ${ }^{\oplus}$ and DBX ${ }^{\circledR}$ ) and local autograft. Next, $7.5 \mathrm{cc}$ of Grafton ${ }^{\oplus}$ DBM/local autograft composite was implanted on the left side, and the same amount of DBX ${ }^{\circledR}$ DBM/local autograft composite was implanted on the right side in the same patient. The PLF masses of 54 total sides (27 Grafton ${ }^{\circledR}$ sides and 27 DBX ${ }^{\circledR}$ sides) were assessed for fusion based on both flexion/extension lateral radiographs and computed tomography images at 12 and 24 months postoperatively. Clinical symptoms were also evaluated.

Results: At 12 months postoperatively, the fusion rates for the Grafton ${ }^{\oplus}$ and DBX ${ }^{\circledR}$ sides were 59.5 and $51.9 \%$, respectively; the difference was not statistically significant $(P=0.425)$. At 24 months postoperatively, the fusion rates for the Grafton ${ }^{\oplus}$ and DBX ${ }^{\circledast}$ sides increased to 70.4 and $66.7 \%$, respectively, but the difference was still not statistically significant $(P=0.574)$. Diabetes mellitus, smoking, and obesity (body mass index $\geq 25$ ) negatively affected the fusion rate of both the Grafton ${ }^{\oplus}$ and DBX ${ }^{\circledR}$ sides. Visual analog scores for lower back pain and leg pain and Oswestry Disability Index were significantly improved after surgery (both, $P<0.01$ ). No deep or superficial infections occurred postoperatively. No patients underwent revision surgery due to nonunion during follow-up.

Conclusions: Our results suggest that two kinds of DBMs/local autograft composites might be considered as useful bone graft substitute in instrumented posterolateral fusion for lumbar spinal stenosis or degenerative spondylolisthesis less than grade 1.
\end{abstract}

Keywords: Demineralized bone matrix, Local autograft, Composite, Instrumented posterolateral fusion, Bone graft substitute

\footnotetext{
* Correspondence: spinepjb@catholic.ac.kr

${ }^{2}$ Department of Orthopaedic Surgery, College of Medicine, The Catholic

University of Korea, Seoul, South Korea

${ }^{3}$ Department of Orthopaedic Surgery, Uijeongbu St. Mary's Hospital, College

of Medicine, The Catholic University of Korea, Korea, 271 Cheonbo-ro,

Uijeongbu-si, Gyeonggi-do 11765, South Korea

Full list of author information is available at the end of the article
}

(c) The Author(s). 2021 Open Access This article is licensed under a Creative Commons Attribution 4.0 International License, which permits use, sharing, adaptation, distribution and reproduction in any medium or format, as long as you give appropriate credit to the original author(s) and the source, provide a link to the Creative Commons licence, and indicate if changes were made. The images or other third party material in this article are included in the article's Creative Commons licence, unless indicated otherwise in a credit line to the material. If material is not included in the article's Creative Commons licence and your intended use is not permitted by statutory regulation or exceeds the permitted use, you will need to obtain permission directly from the copyright holder. To view a copy of this licence, visit http://creativecommons.org/licenses/by/4.0/. The Creative Commons Public Domain Dedication waiver (http://creativecommons.org/publicdomain/zero/1.0/) applies to the data made available in this article, unless otherwise stated in a credit line to the data. 


\section{Background}

Lumbar spinal fusion procedures are usually performed for lumbar degenerative diseases when preoperative instability is present or when postoperative instability is expected due to the extensive decompression required during surgery [1-8]. The ultimate aim of lumbar spinal fusion procedures is to achieve solid fusion at the index level. Ideal graft materials or graft substitutes should have three basic biologic attributes: osteogenicity, osteoconductivity, and osteoinductivity [9-18]. An autologous iliac crest bone graft (ICBG) is the gold standard for lumbar spinal fusion procedures because the substantial amount of cancellous bone that can be obtained from the inner table of the pelvis provides all the desired graft properties [18-30]. However, the morbidity rates associated with autologous ICBG use are high, with some studies reporting up to a $40 \%$ rate of persistent donor site pain, paresthesia, hematoma, and infection [11-14]. Potential alternatives to autologous ICBG, including local autograft, calcium-phosphate salts, demineralized bone matrix (DBM), the bone morphogenetic proteins (BMP) family, autogenous growth factors, bone marrow aspirate, and collagen base matrices, are gaining popularity and are being increasingly used in lumbar spinal fusion procedures [1-7]. Recently, the osteoinductive potential of allogeneic DBM has been studied as an alternative bone graft materials. There are several commercially available DBMs according to the carriers, especially hyaluronic acid $\left(\mathrm{DBX}^{\circ}\right)$ carriers and glycerol carriers $\left(\mathrm{Grafton}^{\circ}\right)$ and the form of the carrier choice of DBM may cause a difference of surgical outcomes.

It is vital to achieve a solid union following lumbar spinal fusion procedures because pseudarthrosis often causes disappointing clinical outcomes and often necessitate further revision surgery [8-10]. However, much controversy exists between fusion rates and clinical outcomes because a successful bony union does not always produce improved clinical outcomes [31, 32]. To the best of our knowledge, no prior studies have undertaken side-by-side comparisons of the fusion efficacy of two types of DBMs/local autograft composites for instrumented posterolateral lumbar fusion (PLF) in the same patients.

\section{Methods}

\section{Study design}

The inclusion criteria for this study were (1) spinal stenosis or degenerative spondylolisthesis less than grade 1 without instability; (2) a minimum follow-up period of 24 months after surgery; (3) follow-up radiology with plain radiographs including flexion/extension lateral radiographs and computed tomography (CT) both 12 and 24 months postoperatively; and (4) clinical assessment 12 and 24 months postoperatively. Exclusion criteria were (1) a history of previous spine surgery, (2) the presence of degenerative spondylolisthesis greater than grade 1, and (3) PLF with interbody fusion. Of the 22 patients, finally a total of 19 patients met the inclusion criteria and included in the study, whereas 3 patients were excluded due to lack of follow-up data.

In the current study, we used and assessed the fusion efficacy of Grafton ${ }^{\circ}$ (Medtronic Sofamor Danek, Memphis, TN, USA) and DBX (Musculoskeletal Transplant Foundation, Edison, NJ, USA) DBMs/local autograft composites in instrumented PLF procedures. From November 2016 to October 2017, 22 patients underwent decompression and instrumented PLF using Grafton ${ }^{\circ}$ or DBX $^{\circ}$ DBMs/local autograft composite for one- to three-level surgeries from L2-3 to L4-5. All patients complained of lower back pain and leg pain with claudication that was unresponsive to conservative treatment for at least 3 months. The diagnosis was based on clinical symptoms, plain radiographs (including flexion/extension lateral radiographs), CT, and magnetic resonance imaging (MRI). Nineteen patients met all the inclusion criteria and were included in the study. However, three of these patients were subsequently excluded because they did not undergo follow-up CT performed within 24 months postoperatively. All data were collected prospectively but were retrospectively analyzed to characterize the fusion efficacy of two DBMs/local autograft composites for instrumented PLF. This research was approved by the Institutional Review Board of the Uijeongbu St. Mary's Hospital. All participants agreed with the data and publication of the manuscript and all participants provided written informed consent. All declarations were performed in accordance with the relevant guidelines and regulations.

\section{Demographic data}

Demographic data for the 19 patients are summarized in Table 1. The mean age at the time of surgery was 65.7 years (range: 43-82). Eight patients were male, and 11 were female. Thirteen patients underwent one-level surgery; four patients had two-level surgery, and two patients underwent three-level surgery. The majority of one-level fusions were performed at the L4-5 level (11 patients). The other two one-level fusions took place at the L2-3 and L3-4 levels. All four two-level fusions were performed at the L3-5 levels, and both three-level fusions were performed at the L2-5 levels, respectively. Eight patients (42\%) had diabetes mellitus (DM), and four $(21 \%)$ were current smokers. The mean body mass index (BMI) was 24.9 (range: 20.1-30.2); nine patients (47\%) had a BMI $<25$, and 10 patients (53\%) had a $\mathrm{BMI} \geq 25$, which was considered obese including overweight. The mean follow-up period length after surgery was 33.8 months (range: $24-48$ months).

Two DBMs/local autograft composites. 
Table 1 Demographic data for Grafton ${ }^{\oplus}$ DBM/local autograft and DBX DBM/local autograft composites for instrumented posterolateral fusion

\begin{tabular}{ll}
\hline Mean age (years) & 65.7 (range: 43-82) \\
Sex (male/female) & $8 / 11$ \\
Mean follow-up (months) & 33.8 (range: 24-48) \\
Surgery (fused segment) & 19 \\
One-level & $13(58 \%): 11$ L4-5, 1 L3-4, 1 L2-3 \\
Two-level & $4(21 \%): 4$ L3-4-5 \\
Three-level & $2(11 \%): 2$ L2-3-4-5 \\
Diabetes mellitus & $8(42 \%)$ \\
Smoking & $4(21 \%)$ \\
Mean BMI & $24.9($ range: 20.1-30.2) \\
BMl <25 & $9(47 \%)$ \\
BMI $\geq 25$ & $10(53 \%)$ \\
Pedicle screw system & 19 \\
Optima & $12(63 \%)$ \\
CD Horizon Legacy & $4(21 \%)$ \\
Iliad & $3(16 \%)$ \\
\hline
\end{tabular}

$D B M$ Demineralized bone matrix, $B M I$ Body mass index

All surgeries were performed by a single senior spine surgeon. Local autobone was harvested from the spinous process, lamina, and facet joints during decompression and was cleaned of any remnant soft tissue and minced into pieces. The local autobone was divided evenly per side and per fusion segment. The PLF mass consisted of DBM and local autograft at a 1:2 ratio. The average amount of local autograft used per side was $5 \mathrm{cc}$ (range: 4-6 ccs). For left-side fused segments, 2.5 cc of Grafton ${ }^{\circ}$ DBM was combined with local autograft to form a composite graft. A 7.5-cc Grafton ${ }^{\circ}$ DBM/local autograft composite was placed in the posterolateral gutters to bridge the intertransverse process space. For right-side fused segment(s), $2.5 \mathrm{cc}$ of $\mathrm{DBX}{ }^{\circ} \mathrm{DBM}$ was prepared in the same manner as the Grafton ${ }^{\circ} \mathrm{DBM} /$ local autograft composite, and $7.5 \mathrm{cc}$ of $\mathrm{DBX}^{\circ} \mathrm{DBM} /$ local autograft composite were implanted during the same procedure in the same patient. No additional graft material, graft extenders, or enhancers were used. This unique study design with two DBMs implanted simultaneously in the same patient enabled each patient to serve as his or her own control.

\section{Fusion assessment}

The patients were routinely followed up with plain radiographs that included flexion/extension lateral radiographs at 6 weeks and then at 3, 6, 12, and 24 months postoperatively. Additionally, a $1-\mathrm{mm}$ slice coronal CT was assessed to more accurately evaluate the fusion status after PLF at 12 and 24 months postoperatively. To determine the fusion status, two independent and blinded spine surgeons evaluated the postoperative anteroposterior and flexion/extension lateral radiographs and CTs. If the surgeons' assessments did not agree, a third spine surgeon evaluated the films, and his assessment was used as the final result. Three criteria were used to determine fusion success at the surgical level: $(1)<3^{\circ}$ of angulation on flexion/extension lateral radiographs, (2) $<2 \mathrm{~mm}$ of translation on flexion/extension lateral radiographs, and (3) bridging bone connecting the transverse process on consecutive $1-\mathrm{mm}$ coronal images from CT. The fusion mass lateral to the instrumentation on each side of the fusion segment was independently judged as being fused or not (Fig. 1). Therefore, 54 total sides (27 Grafton ${ }^{\circ}$ sides and $27 \mathrm{DBX}^{\circ}$ sides) of 27 fusion segments in 19 patients were evaluated (Fig. 2). Fusion was only deemed successful if all three criteria were met, which is a very strict standard compared with those used in previous studies (Fig. 3) [8, 11, 14]. Finally, we examined the effects of DM, smoking, and obesity $(\mathrm{BMI} \geq 25)$ on the fusion status for the two DBM/local autobone composite grafts 24 months postoperatively.

\section{Clinical evaluation}

A 10-point visual analog scale (VAS) was administered to evaluate lower back pain and leg pain preoperatively, at each follow-up time point, and again at 24 months postoperatively. The Oswestry Disability Index (ODI) was used to evaluate any pain and disability caused by the spinal condition preoperatively, at each follow-up time point, and at 24 months postoperatively.

\section{Statistical analysis}

A Chi-square test and paired t-test were used for the statistical analyses. $P$-values $<0.05$ were considered statistically significant.

\section{Results}

The fusion rates for the two DBMs/local autograft composites for instrumented PLF are summarized in Table 2. At 12 months postoperative, the fusion rates of the Grafton $^{\circ}$ and $\mathrm{DBX}^{\circ}$ sides were $59.5 \%$ (16/27 fusion segments) and $51.9 \%(14 / 27)$, respectively. Although the fusion rate of the Grafton ${ }^{\circ}$ side was slightly higher than that of the $\mathrm{DBX}^{\circ}$ side, this difference was not statistically significant $(P=0.425)$. At 24 months postoperative, the fusion rates of the Grafton $^{\circ}$ and $\mathrm{DBX}^{\circ}$ sides had increased to $70.4 \%$ (19/27 fusion segments) and 66.7\% (18/27), respectively. Although the fusion rate of the Grafton side was slightly higher than that of the $\mathrm{DBX}^{\circ}$ side, this difference was not statistically significant $(P=0.574)$.

DM, smoking, and obesity negatively affected the segment fusion status of both DBMs/local autograft 


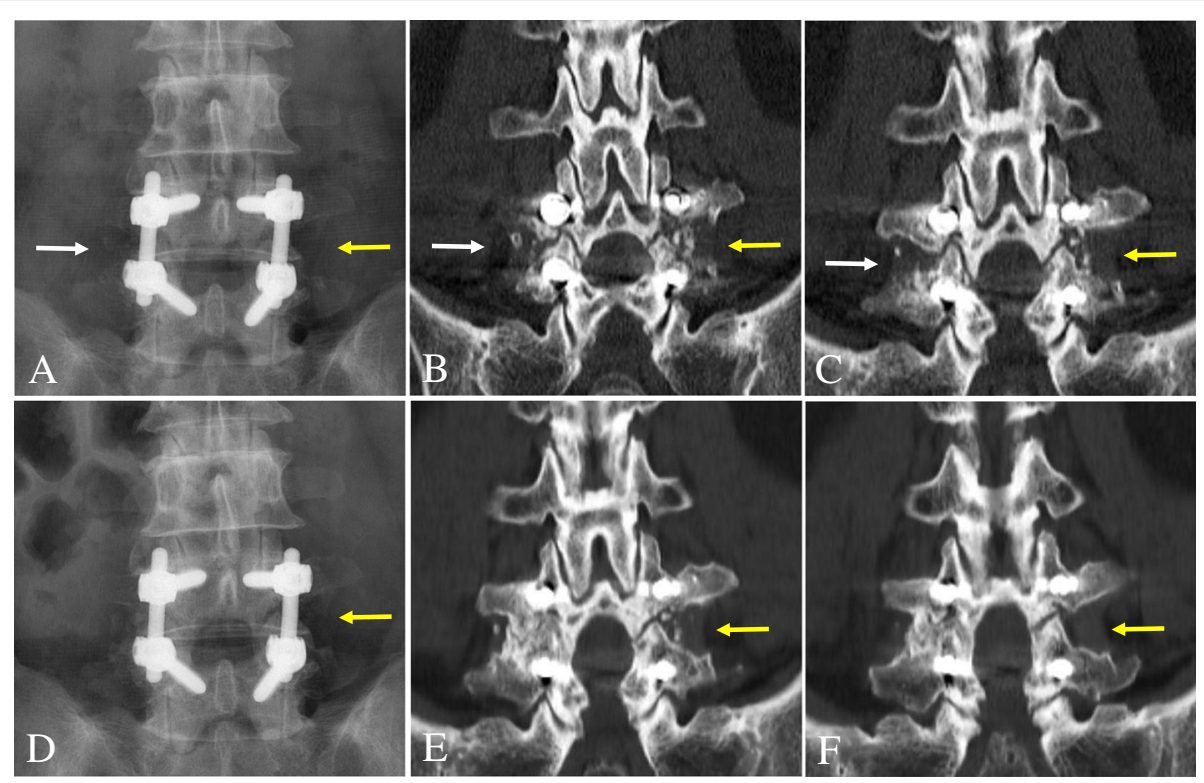

Fig. 1 A 60-year-old male patient underwent decompression and instrumented posterolateral fusion using Grafton (left side) and DBX (right side) DBM/local autograft composites at L4-5. At 12 months postoperative, both sides showed nonunion (white and yellow arrows) on anteroposterior radiograph (a) and coronal two-dimensional computed tomography images (b and $\mathbf{c}$ ). At 24 months postoperatively, the DBX ${ }^{\circledR}$ side was defined as a fusion, but the Grafton ${ }^{\circledast}$ side was labeled as a nonunion (yellow arrows) on anteroposterior radiograph (d) and coronal computed tomography images (e and $\mathbf{f}$ )
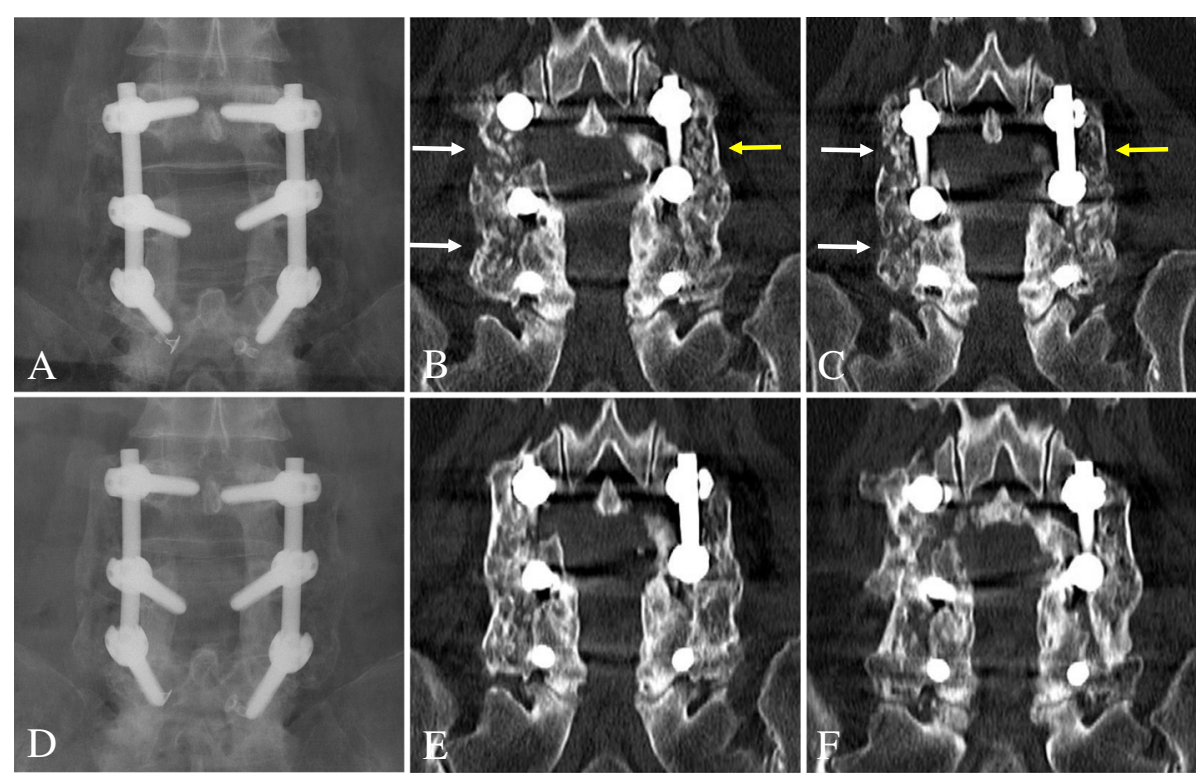

Fig. 2 A 69-year-old female patient underwent decompression and instrumented posterolateral fusion using Grafton ${ }^{\circledast}$ (left side) and DBX ${ }^{\circledR}$ (right side) DBMs/local autograft composites at L3-4-5. At 12 months postoperative, L3-5 on the DBX ${ }^{\circledR}$ side (white arrows) and L3-4 on the Grafton ${ }^{\oplus}$ side (yellow arrow) were defined as nonunions on anteroposterior radiograph (a) and coronal two-dimensional computed tomography images (b and c). At 24 months postoperatively, L3-5 on both sides was defined as fusion on both anteroposterior radiograph (d) and coronal computed tomography images (e and $\mathbf{f}$ ) 


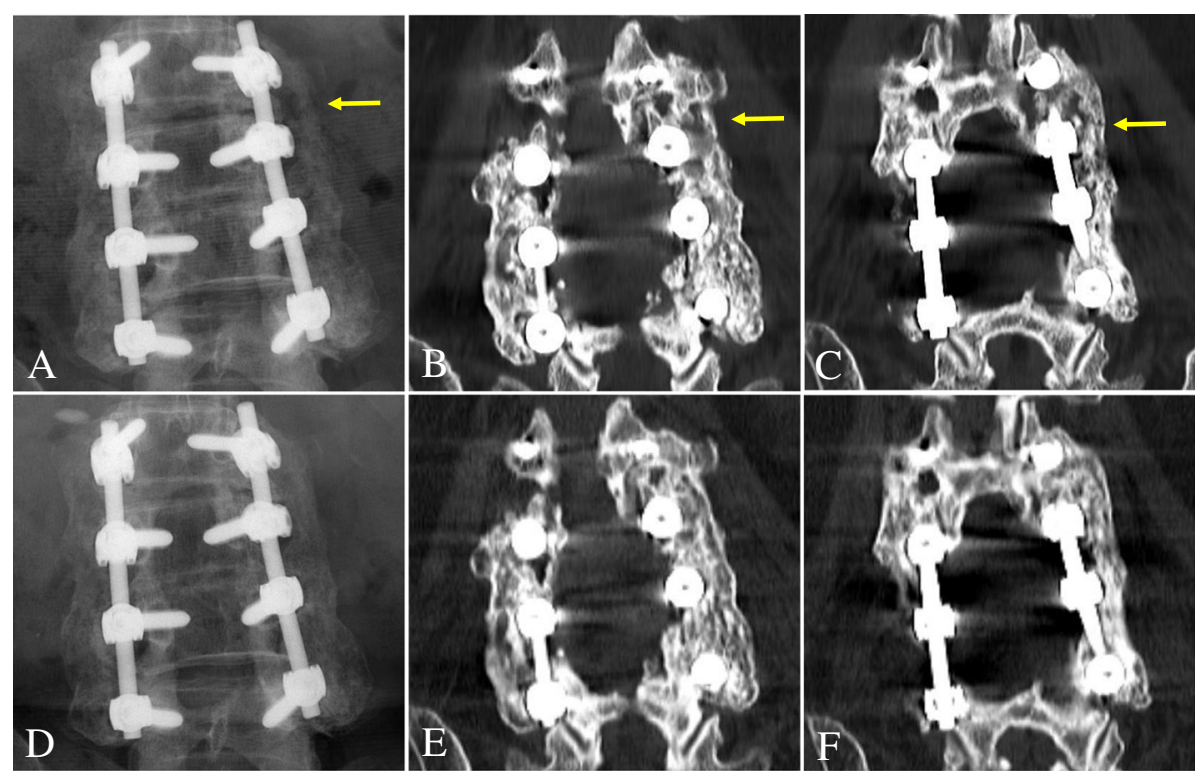

Fig. 3 A 68-year-old female patient underwent decompression and instrumented posterolateral fusion using Grafton ${ }^{\circledast}$ (left side) and DBX ${ }^{\circledR}$ (right side) DBMs/local autograft composites at L2-5. At 12 months postoperatively, L2-5 on the DBX ${ }^{\circledR}$ side was defined as a fusion, but L2-3 on the Grafton ${ }^{\oplus}$ side (yellow arrow) was defined as a nonunion on anteroposterior radiograph (a) and coronal two-dimensional computed tomography images (b and c). At 24 months postoperatively, L2-5 on both sides were defined as fusions on both anteroposterior radiograph (d) and coronal computed tomography images (e and $\mathbf{f}$ )

composites 24 months after instrumented PLF (Table 3). Diabetic $(55.6 \%$ vs. $75.0 \%, P<0.01)$, smoking $(58.3 \%$ vs. $71.4 \%, P<0.05$ ), and obese ( $\geq \mathrm{BMI}=25 ; 46.7 \%$ vs. $87.5 \%$, $P<0.01)$ patients had lower fusion rates compared to non-exposed patients.

Clinical symptoms significantly improved after surgery (Table 4). The preoperative VAS scores for lower back pain and leg pain were $4.9 \pm 1.7$ and $7.2 \pm 2.1$, respectively; at 24 months after surgery, the VAS values decreased significantly to $2.1 \pm 0.7$ and $1.9 \pm 0.8$, respectively $(P<0.01$ for both). Preoperative ODI was $42 \pm 14.0$, which decreased significantly at 24 months postoperative to $21 \pm 6.0(P<0.01)$. No deep or superficial infections occurred postoperatively. No patients underwent revision surgery due to nonunion during follow-up.

\section{Discussion}

DBM is an acid extraction product of cadaver bone that was first developed by Marshall Urist in 1965 [33].
While most bone graft substitutes and synthetics are osteoconductive rather than osteoinductive, DBM has osteoinductive properties with the potential to aid in spinal fusion [21]. There are several commercially available DBM substances that are currently used in spinal surgery with different concentrations of osteoinductive proteins [21, 22]. The carrier choice is one important factor because it can affect the fusion efficacy and/or rate. As opposed to the neutral $\mathrm{pH}$ of hyaluronic acid $\left(\mathrm{DBX}^{\oplus}\right)$ carriers, negative effects have been observed with the use of glycerol carriers (Grafton ${ }^{\circledR}$ ), which generate a highly acidic environment for host tissues, especially when used in large quantities at the fusion site [24, 34]. These previous studies have shown that commercially available DBM products exhibit significant variability in fusion performance, which is secondary to their differences in carrier medium and processing [24, 34].

DBM has been studied as a bone graft extender, enhancer, and substitute in animal models and has demonstrated significant intra-and inter-product performance

Table 2 Comparative analysis of fusion rate of Grafton ${ }^{\oplus}$ and DBX ${ }^{\circledR}$ DBMs/local autograft composites at 12 and 24 months after instrumented posterolateral fusion

\begin{tabular}{llll}
\hline & \multicolumn{2}{l}{ Fusion Rate (\%) } & $P$-value \\
\cline { 2 - 3 } & Grafton ${ }^{\circledR}$ side $(\boldsymbol{n}=\mathbf{2 7})$ & DBX $^{\oplus}$ side $(\boldsymbol{n}=\mathbf{2 7})$ & \\
\hline Postoperative 12 months & $59.5 \%(16 / 27)$ & $51.9 \%(14 / 27)$ & $P=0.425$ \\
Postoperative 24 months & $70.4 \%(19 / 27)$ & $66.7 \%(18 / 27)$ & $P=0.574$ \\
\hline
\end{tabular}


Table 3 Negative effect of diabetes mellitus, smoking, and obesity on fusion status of Grafton ${ }^{\oplus}$ and DBX ${ }^{\circledR}$ DBMs/local autograft composites in instrumented posterolateral fusion

\begin{tabular}{|c|c|c|c|}
\hline & \multicolumn{2}{|c|}{$\begin{array}{l}\text { Fusion Status } \\
\left(N=54 ; 27 \mathrm{Grafton}^{\otimes} \text { side }+27 \mathrm{DBX}^{\oplus} \text { side }\right)\end{array}$} & \multirow[t]{2}{*}{$P$-value } \\
\hline & Fused & Not Fused & \\
\hline Diabetes mellitus & & & $P<0.01$ \\
\hline No $(n=36)$ & $75.0 \%(27 / 36)$ & $25.0 \%(9 / 36)$ & \\
\hline Yes $(n=18)$ & $55.6 \%(10 / 18)$ & $44.4 \%(8 / 18)$ & \\
\hline Smoking & & & $P<0.05$ \\
\hline No $(n=42)$ & $71.4 \%(30 / 42)$ & $28.6 \%(12 / 42)$ & \\
\hline Yes $(n=12)$ & $58.3 \%(7 / 12)$ & $41.7 \%(5 / 12)$ & \\
\hline Obesity $^{a}$ & & & $P<0.01$ \\
\hline $\mathrm{BMI}(<25)(n=24)$ & $87.5 \%(21 / 24)$ & $12.5 \%(3 / 24)$ & \\
\hline $\mathrm{BMI}(\geq 25)(n=30)$ & $46.7 \%(16 / 30)$ & $53.3 \%(14 / 30)$ & \\
\hline
\end{tabular}

Obesity including both overweight and obesity; DBM Demineralized bone matrix, BMI Body mass index

variability [1-15]. However, there is little formal clinical evidence of its efficacy in instrumented PLF surgery [35-39]. Furthermore, much controversy exists regarding fusion rates and clinical outcomes because a successful bony union does not always result in improved clinical outcomes [31, 32]. Therefore, we tried to suggest a guideline for obtaining improved fusion rates and good clinical outcomes in the treatment of spinal stenosis or degenerative spondylolisthesis less than grade 1 without instability using DBM/local autograft composite without ICBG. To the best of our knowledge, no studies have undertaken a side-by-side comparison of the fusion efficacy of two kinds of DBMs/local autograft composites for instrumented PLF in the same patients. Therefore, we performed the current study to assess the fusion efficacy of two kinds of DBMs (Grafton ${ }^{\odot}$ and $\mathrm{DBX}^{\odot}$ )/local autograft composites in instrumented PLF using a sideby-side comparison.

Regarding the fusion rate, our study found no significant differences between the two DBMs/local autograft groups at 12 and 24 months postoperatively, even though the fusion rate of the Grafton ${ }^{\bullet}$ side was slightly higher than that of the $\mathrm{DBX}^{\oplus}$ side. In a Level I prospective multicenter randomized clinical trial, Kang et al. [14]. evaluated the efficacy of a DBM preparation

Table 4 Clinical outcomes of Grafton ${ }^{\oplus}$ DBM/local autograft and DBX ${ }^{\circledR}$ DBM/local autograft composites in instrumented posterolateral fusion

\begin{tabular}{llll}
\hline & Preoperative & Postoperative 24 month & $P$-value \\
\hline VAS & & & \\
Lower back pain & $4.9 \pm 1.7$ & $2.1 \pm 0.7$ & $P<0.01$ \\
Leg pain & $7.2 \pm 2.1$ & $1.9 \pm 0.8$ & $P<0.01$ \\
ODI & $42 \pm 14$ & $21 \pm 6$ & $P<0.01$
\end{tabular}

DBM Demineralized bone matrix, VAS Visual analog scale, ODI Oswestry Disability Index
(Grafton ${ }^{\oplus}$ ) compared with an iliac crest autograft for one-level posterior lumbar fusion. The arthrodesis rate was evaluated using plain radiographs and CT scans and was $86 \%$ in the DBM group and $92 \%$ for the autograft group $(P=1.0)$, which indicated that the fusion rates and clinical outcomes associated with DBM were comparable to those of an iliac crest autograft. In their Level II study, Cammisa et al. [8] investigated the role of DBM as a fusion extender in conjunction with an autograft in 120 patients who underwent instrumented PLF. In each patient, an iliac crest autograft was implanted on one side of the spine, and a DBM (Grafton ${ }^{\odot}$ )/autograft composite was implanted on the contralateral side. The authors concluded that DBM was an effective graft extender because it decreased the amount of autograft required and potentially reduced the risk for and severity of donorsite morbidity, however special attention would be needed to the fusion rate when performing the instrumented PLF with DBMs/local autograft composites only. Vaccaro et al. [38] conducted a Level II prospective study that evaluated DBM (Grafton ${ }^{\odot}$ ) use in instrumented PLF in 19 patients along with supplemental bone grafting with DBM putty enriched with aspirated bone marrow, 27 patients who had DBM putty combined with an iliac crest autograft, and 27 control-group patients who received only an autograft. After 24 months, $63 \%$ of the levels in the DBM/bone marrow group, $70 \%$ of the levels in the DBM/iliac crest group, and $67 \%$ of the levels in the autologous ICBG group demonstrated radiological fusion on anteroposterior, lateral, and flexion/extension radiographs $(P=0.875)$.

In this study, we used DBM combined with local autograft harvested from the spinous process, lamina, and facet joints during decompression. Many studies have reported that DBM combined with autologous laminectomy bone and osteoconductive materials is as effective as an autologous iliac bone graft at achieving long multi- 
segment posterolateral fusion success [11, 39, 40]. Through the combination of DBM and local autograft, custom bone graft composites can provide all three components necessary for bone formation: osteogenesis, osteoinduction, and osteoconduction. This combination can be used as an effective bone graft substitute for multi-segment PLF and may decrease morbidities associated with autogenous ICBG [11].

Many factors have an impact on fusion success, including surgical technique, primary or revision surgery, instrumentation, grafting materials, and patient comorbidities [41, 42]. Several studies have highlighted the deleterious effects of advanced age, osteoporosis due to slowed bone metabolism, and a decreased differentiating capacity of osteoprogenitor cells [1-3]. Our study showed that DM, smoking, and obesity negatively affected the fusion status of both DBMs/local autograft composites at 24 months after instrumented PLF. Therefore, it is important to consider these comorbidities when selecting the DBM/local autograft composite type for instrumented PLF to ensure the best fusion rate and improve surgical and clinical outcomes.

Some authors have reported a discrepancy between bone union status and clinical outcomes, and a successful bony union does not always lead to satisfactory clinical outcomes [31, 32]. In addition, there is controversy over the fact that successful fusion guarantees good clinical results. In some cases, successful fusion can often cause pain, while other patients with non-unions do not report pain. Fischgrund et al. [31] found that successful arthrodesis occurred in $83 \%$ of the instrumented PLF procedures. However, successful fusion was not predictive of a successful patient outcome. Herkowitz et al. [32] reported that pseudarthrosis was seen in about $36 \%$ of patients, but the clinical results were excellent; their study concluded that the development of a fibrous union appeared to provide sufficient structural support to prevent progressive spondylolisthesis. Similarly, our study showed comparable clinical outcomes showing successful response to conservative treatment despite the relatively lower fusion rates of about $70 \%$ after instrumented PLF. This finding may be due to the inclusion of study patients with spinal stenosis or degenerative spondylolisthesis less than grade 1 and fibrous union using a minimally invasive surgical technique with preservation of the facet joint capsule, which resulted in relatively good clinical outcomes even if a fibrous union occurred instead of a solid union. We concluded that the fusion efficacies and clinical outcomes of Grafton $^{\circ}$ and DBX $^{\circ}$ DBM/local autograft composite were improved after instrumented PLF for lumbar spinal stenosis or degenerative spondylolisthesis less than grade 1 , which is a good indication for the use of DBM/local autograft composite without ICBG. However, careful caution should be pay attention to its use in consideration of the patient's characteristics. Additionally, it is important to achieve circumferential fusion including both posterolumbar interbody fusion and posterolateral fusion in a lumbar spinal fusion. This study is focused on the fusion rates of spinal stenosis or degenerative spondylolisthesis less than grade using two kinds of DBM/local autologous bone composite. Therefore, when multilevel fusion surgery is planned, we recommend circumferential fusion be performed by both posterolateral fusion and interbody fusion, regardless of fusion materials.

In this study, the fusion rate was slightly lower than that noted in previous reports $[8,11,14]$, which likely reflected our strict criteria for bone union. Measurements were obtained from dynamic radiographs for a definitive evaluation of the fusion status. We defined pseudarthrosis as angular motion $<3^{\circ}$ and $2 \mathrm{~mm}$ of sagittal motion at a Cobb angle on postoperative flexion/extension radiographs. Because the instrumentation used in this study might have inhibited motion on the dynamic radiographs, we also assessed the $\mathrm{CT}$ images for a fusion mass. CT scanning has superior sensitivity to bone growth in the graft area compared with simple radiographs and offers useful visualization of growing bone bridges [43]. In this study, we collected coronal and sagittal images of patients to identify whether the cranial and caudal endplates were connected by vertical bone bridges [10]. When interpreting the fusion status using CT scans, most previous studies have focused on the presence and continuity of bone bridges [10-12]. In patients who had more than one-level fusions, each level was evaluated independently for segment fusion, and the entire set of levels had to show continuity in the fusion mass to be considered overall fusion, while the observation of a one-level pseudarthrosis was considered unfused [10-12].

This study had some limitations. The sample size was relatively small to provide a meaningful analysis and the comparative analysis overestimates the differences between the two groups. However, to the best of our knowledge, this is the first study to perform side-by-side comparisons of fusion efficacy between two DBMs/local autograft composites for graft extension and enhancement after instrumented PLF with unusual peculiar clinical model. Moreover, the self-control design of this study, wherein two different DBMs were implanted on each side in the same patient, eliminated the effects of patient comorbidities, such as DM, smoking, and obesity, which is a great advantage.

\section{Conclusion}

The fusion rates of two kinds of DBMs/local autograft composites was similar of about $70 \%$ with improvement of clinical symptoms for lumbar spinal stenosis or 
degenerative spondylolisthesis less than grade 1 . Our results suggest that two kinds of DBMs/local autograft composites might be considered as useful bone graft substitute in instrumented posterolateral fusion for lumbar spinal stenosis or degenerative spondylolisthesis less than grade 1.

\section{Abbreviations}

ICBG: Iliac crest bone graft; DBM: Demineralized bone matrix; BMP: Bone morphogenetic proteins; PLF: Posterolateral lumbar fusion; CT: Computed tomography; MRI: Magnetic resonance imaging; DM: Diabetes mellitus; BMI: Body mass index; VAS: Visual analog scale; ODI: Oswestry Disability Index

\section{Acknowledgments}

None.

\section{Authors' contributions}

DGC: Writing-original draft, Writing-review \& editing. JBP: Conceptualization, Resources, Supervision, Project administration, Writing-review \& editing. $\mathrm{YH}$ : Validation, Data curation. All authors have read and approved the final manuscript.

\section{Funding}

This study was supported by 2020 AOSpine National Research Grant (AOSKR(R)2020-01).

\section{Availability of data and materials}

The datasets used and/or analyzed during the current study are available from the corresponding author on reasonable request.

\section{Ethics approval and consent to participate}

This research was approved by the Institutional Review Board of the Uijeongbu St. Mary's Hospital. All participants agreed with the data and publication of the manuscript and all participants provided written informed consent.

\section{Consent for publication}

The authors have obtained the patient's written informed consent for print and electronic publication of this research

\section{Competing interests}

The authors declare that they have no conflict of interest.

\section{Author details}

'Department of Orthopaedic Surgery, College of Medicine, Inje University Sanggye Paik Hospital, Inje University, Seoul, South Korea. ${ }^{2}$ Department of Orthopaedic Surgery, College of Medicine, The Catholic University of Korea, Seoul, South Korea. ${ }^{3}$ Department of Orthopaedic Surgery, Uijeongbu St. Mary's Hospital, College of Medicine, The Catholic University of Korea, Korea, 271 Cheonbo-ro, Uijeongbu-si, Gyeonggi-do 11765, South Korea.

Received: 14 October 2020 Accepted: 8 February 2021

\section{Published online: 17 February 2021}

\section{References}

1. Buser Z, Brodke DS, Youssef JA, et al. Allograft versus demineralized bone matrix in instrumented and noninstrumented lumar fusion: a symstemic review. Global Spine J. 2018:8:396-412.

2. Kadam A, Millhouse PW, Kepler CK, et al. Bone substitutes and expanders in spine surgery: a review of their fusion efficacies. Int J Spine Surg. 2016;10:33 eCollection 2016.

3. Kaiser MG, Groff MW, Watters WC 3rd, et al. Guideline update for the performance of fusion procedures for degenerative disease of the lumbar spine: part 16: bone graft extenders and substitutes as an adjunct for lumbar fusion. J Neurosurg Spine. 2014;21:106-32.

4. Park JJ, Hershman SH, Kim YH. Update in the use of bone grafts in the lumbar spine. Bull Hosp Jt Dis. 2013:71:39-48.

5. Hsu WK, Nickoli MS, Wang JC, et al. Improving the clinical evidence of bone graft substitute technology in lumbar spine surgery. Global Spine J. 2012;2: 239-48.
6. Abdullah KG, Steinmetz MP, Benzel EC, Mroz TE. The state of lumbar fusion extenders. Spine (Phila Pa 1976). 2011;36:E1328-34.

7. Rihn JA, Kirkpatrick K, Albert TJ. Graft options in posterolateral and posterior interbody lumbar fusion. Spine (Phila Pa 1976). 2010;35:1629-39.

8. Cammisa FP Jr, Lowery G, Garfin SR, et al. Two-year fusion rate equivalency between Grafton DBM gel and autograft in posterolateral spine fusion: a prospective controlled trial employing a side-by-side comparison in the same patient. Spine (Phila Pa 1976). 2004;29:660-6.

9. Ajiboye RM, Eckardt MA, Hamamoto JT, et al. Does age influence the efficacy of dimeralized bone matrix enriched with concentrated bone marrow aspirate in lumbar fusions? Clin Spine Surg. 2018;31:E30-5.

10. Kim BJ, Kim SH, Lee H, et al. Demineralized bone matrix (DBM) as a bone void filler in lumbar interbody fusions: a prospective pilot study of simultaneous DBM and autologous bone grafts. J Korean Neurosurg Soc. 2017:60:225-31.

11. Fu TS, Wang IC, Lu ML, et al. The fusion rate of demineralized bone matrix compared with autogenous iliac bone graft for long multi-segment posterolateral spinal fusion. BMC Musculoskelet Disord. 2016;17:3.

12. Kim DH, Lee N, Shin DA, et al. Matched comparison of fusion rates between hydroxyapatite demineralized bone matrix and autograft in lumbar interbody fusion. J Korean Neurosurg Soc. 2016:59:363-7.

13. Ahn DK, Moon SH, Kim TW, Boo KH, Hong SW. Demineralized bone matrix, as a graft enhancer of auto-local bone in posterior lumbar interbody fusion. Asian Spine J. 2014:8:129-37.

14. Kang J, An H, Hilibrand A, et al. Grafton and local bone have comparable outcomes to iliac crest bone in instrumented single-level lumbar fusions. Spine (Phila Pa 1976). 2012;37:1083-91.

15. Schizas C, Triantafyllopoulos D, Kosmopoulos V, Tzinieris N, Stafylas K. Posterolateral lumbar spine fusion using a novel demineralized bone matrix: a controlled case pilot sutdy. Arch Orthop Trauma Surg. 2008;128:621-5.

16. Ricart PH, Gandhi SD, Geisinger J, Baker K, Park DK. Clinical anc CT analysis of lumbar spine arthorodesis: $\beta$-tricalcium phosphate versus demineralized bone matrix. J Am Acad Orthop Surg Glob Res Rev. 2018;2:e024.

17. Gatam AR, Gatam L, Lumban Tobing SD. Comparison of clinical and radiological outcomes of lumbar interbody fusion. Asian Spine J. 2017;11: 706-14.

18. Nam WD, Yi J. Bone union rate following instrumented posterolateral lumbar fusion: comparison between demineralized bone matrix versus hydroxyapatite. Asian Spine J. 2016;6:1149-56.

19. Choi YS, Kim DH, Park JH, Johnstone B, Yoo JU. Effectiveness of posterolateral lumbar fusion varies with the physical properties of demineralized bone matrix strip. Asian Spine J. 2015;9:433-9.

20. Ajiboye RM, Eckardt MA, Hamamoto JT, et al. Outcomes of demineralized bone matrix enriched with concentrated bone marrow aspirate in lumbar fusion. Int J Spine Surg. 2016;10:35 eCollection 2016.

21. Wang JC, Alanay A, Mark D, et al. A comparison of commercially available demineralized bone matrix for spinal fusion. Eur Spine J. 2007:16:1233-40.

22. Lee YP, Jo M, Luna M, et al. The effcicay of different commercially available demineralized bone matrix substances in an athymic rat model. J Spinal Disord Tech. 2005;18:439-44

23. Inage K, Ohtori S, Koshi T, et al. One, two-, and three-level instrumented posterolateral fusin of the lumbar spine with a local bone graft. Spine (Phila Pa 1976). 2011:36:1392-6.

24. Aghdasi B, Montgomery SR, Daubs MD, Wang JC. A review of demineralized bone matrices for spinal fusion: the evidence for efficacy. Surgeon. 2013;11: 39-48.

25. Brecevich AT, Kiely PD, Yoon BV, et al. Efficacy comparison of Accell Evo3 and Grafton demineralized bone matrix putties against autologous bone in a rat posterolateral spine fusion model. Spine J. 2017;17:855-62.

26. Peterson $B$, Whang PG, Iglesias R, Wang JC, Lieberman JR. Osteoinductivity of commercially available demineralized bone matrix. Preparations in a spine fusion model. J Bone Joint Surg Am. 2004;86:2243-50.

27. Park DK, Roberts $R$, Arnold $P$, et al. Lumbar spine fusion rates with local bone in posterolateral and combined posterolateral and interbody approaches. J Am Acad Orthop Surg Glob Res Rev. 2019;3:e018.

28. Lee $\mathrm{JH}$, Hwang $\mathrm{CJ}$, Song BW, et al. A prospective consecutive study of instrumented posterolateral lumbar fusion using synthetic hydroxyapatite (Bongros-HA) as a bone graft extender. J Biomed Mater Res A. 2009;90:80410.

29. Zhang $H$, Yang $L$, Yang $X G$, et al. Demineralized bone matrix carriers and their clinical applications: an overview. Orthop Surg. 2019;11:725-37. 
30. Tilkeridis $\mathrm{K}$, Touzopoulos $\mathrm{P}$, Ververidis $\mathrm{A}$, et al. Use of demineralized bone matrix in spinal fusion. World J Orthop. 2014;5:30-7.

31. Fischgrund JS, Mackay M, Herkowitz HN, et al. Degenerative lumbar spondylolisthesis with spinal stenosis: a prospective, randomized study comparing decompressive laminectomy and arthrodesis with and without spinal instrumentation. Spine (Phila Pa 1976). 1997;22:2807-12.

32. Herkowitz HN, Kurz LT. Degenerative lumbar spondylolisthesis with spinal stenosis. A prospective study comparing decompression with decompression and intertransverse process arthrodesis. J Bone Joint Surg Am. 1991;73:802-8.

33. Urist MR. Bone: formation by autoinduction. Science. 1965;150:893-9.

34. Wang JC, Kanim LE, Nagakawa IS, et al. Does-dependent toxicity of a commercially avalable demineralized bone matrix material. Spine (Phila Pa 1976). 2001;26:1429-35.

35. Thalgott JS, Giuffre JM, Fritts K, Timlin M, Klezl Z. Instrumented posterolateral lumbar fusion using coralline hydroxyapatite with or without demineralized bone matrix, as an adjunct to autologous bone. Spine J. 2001;1:131-7.

36. Sassard WR, Eidman DK, Gray PM, et al. Augmenting local bone with Grafton demineralized bone matrix for posterolateral lumbar spine fusion: avoiding second site autologous bone harvest. Orthopedics. 2000;23:1059-64.

37. Girardi FP, Cammisa FP Jr. The effect of bone graft extenders to enhance the performance of iliac crest bone grafts in instrumented lumbar spine fusion. Orthopedics. 2003;26:e545-8.

38. Vaccaro AR, Stubbs HA, Block JE. Demineralized bone matrix composite grafting for posterolateral spinal fusion. Orthopedics. 2007;30:567-70.

39. Chen WJ, Tsai TT, Chen LH, et al. The fusion rate of calcium sulfate with local autograft bone compared with autologous iliac bone graft for instrumented short-segment spinal fusion. Spine (Phila Pa 1976). 2005;30: 2293-7.

40. Ohtori S, Suzuki M, Koshi T, et al. Single-level instrumented posterolateral fusion of the lumbar spine with a local bone graft versus an iliac crest bone graft: a prospective, randomized study with a 2-year follow-up. Eur Spine J. 2011:20:635-9

41. Glassman SD, Anagnost SC, Parker A, et al. The effect of cigarette smoking and smoking cessation on spinal fusion. Spine (Phila Pa 1976). 2000;25: 2608-15.

42. Okuda S, Oda T, Miyauchi A, et al. Surgical outcomes of posterior lumbar interbody fusion in elderly patients. J Bone Joint Surg Am. 2006;88:2714-20.

43. Lang P, Genant HK, Chafetz N, Steiger P, Morris JM. Three-dimensional computed tomography and multiplanar reformations in the assessment of pseudarthrosis in posterior lumbar fusion patients. Spine (Phila Pa 1976). 1988;13:69-75

\section{Publisher's Note}

Springer Nature remains neutral with regard to jurisdictional claims in published maps and institutional affiliations.

Ready to submit your research? Choose BMC and benefit from:

- fast, convenient online submission

- thorough peer review by experienced researchers in your field

- rapid publication on acceptance

- support for research data, including large and complex data types

- gold Open Access which fosters wider collaboration and increased citations

- maximum visibility for your research: over $100 \mathrm{M}$ website views per year

At $\mathrm{BMC}$, research is always in progress.

Learn more biomedcentral.com/submissions 